\title{
PENGARUH HAMBATAN SAMPING TERHADAP KINERJA JALAN (STUDI KASUS RUAS JALAN DEPAN PASAR MAYONG JEPARA)
}

\author{
Adib Wahyu Hidayat \\ Program Studi Magister Teknik Sipil, Universitas Diponegoro, Semarang \\ Email: adibwah07@gmail.com
}

\begin{abstract}
ABSTRAK
Keberadaan pabrik di sebuah jalan akan memberikan dampak peningkatan jumlah arus lalu lintas dan tingginya nilai hambatan samping pada suatu ruas jalan. Hambatan samping yang tinggi menyebabkan ruas jalan depan pasar Mayong mengalami kemacetan lalu lintas pada jam-jam sibuk. Tujuan kajian ini adalah untuk mengetahui pengaruh hambatan samping terhadap kecepatan tempuh kendaraan ringan dan melihat derajat kejenuhan terhadap permasalahan yang ditimbulkan akibat faktor hambatan samping pada ruas jalan depan Pasar Mayong, Jepara melalui analisa hasil pengamatan dengan PKJI 2014. Hasil analisis hubungan hambatan samping (KHS) pada segmen 1 dan kecepatan di ruas jalan depan pasar mayong mengalami hambatan samping sebesar $y=1,6179 x^{2}+74,357 x$. Didapatkan koefisien determinasi sebesar 0,4238 . Nilai koefisien korelasinya 0,651 . Sedangkan hasil analisis hubungan hambatan samping (KHS) pada segmen 2 dan kecepatan di ruas jalan depan pasar mayong mengalami hambatan samping sebesar $y=-6,6333 x^{2}+490,8 x-8666,6$ dan koefisien determinasi sebesar 0,2241 , sedangkan nilai koefisien korelasinya 0,473 .
\end{abstract}

Kata kunci: hambatan samping, derajat kejenuhan, PKJI 2014

\begin{abstract}
The existence of a factory on a road will have an impact on increasing the traffic flow and the high value of other side resistance on a road. This causes the Mayong market's front roads to become more limited during rush hours, thereby reducing the speed and capacity of the reduced road, resulting in traffic congestion. The purpose of this study was to study side interactions with light vehicle travel speeds and see the degree of saturation of problems caused by other factors on the front road of the Mayong Market, Jepara through research findings with the 2014 PKJI. Vehicles coming in and out of the road. The results of the analysis of the side obstacle relationship (KHS) in segment 1 and speed on the road segment in the Mayong market increase the side barriers by $y=-1.6179 x^{2}+74.357 x$ and also obtain a coefficient of determination of 0.4238 , While the correlation coefficient is 0.651 . The results of the side relationship analysis (KHS) in segment 2 and speed on the Mayong market front road repair the side barriers by $y=-6,6333 x^{2}+490,8 x-8666,6$ and also obtained a coefficient of determination of 0.2241 , while the value of the correlation coefficient is 0.473 .
\end{abstract}

Keywords: side resistance, degree of saturation, PKJI 2014

\section{PENDAHULUAN}

Kepadatan kendaraan yang didominasi pekerja pabrik terhitung beberapa kali dalam sehari, dalam hal ini di wilayah kabupaten Jepara. Beberapa titik yang sering mengalamai kepadatan lau lintas di antaranya depan PT. SAMI dan PT. Parkland di ruas Mayong, perempatan pasar Mayong, perempatan keramik Nalumsari, simpang gotri, dan pertigaan PT HWI. Jam pagi yang biasanya diantara pukul 07.00 sampai dengan pukul 08.00 serta pada jam pulang sore diantara pukul 15.30 sampai dengan pukul 16.30. Kepadatan juga ditambah dengan adanya kendaraan-kendaraan besar seperti truk dan kontainer pengangkut barang mebel yang melintas jalan Mayong-Kudus.

Khusus jalan di depan pasar Mayong sendiri berada di jalan strategis di jalan raya Jepara-Kudus, karena menghubungkan jalan dari arah Kudus ke Jepara, begitu juga sebaliknya. Faktor kelancaran arus lalu lintas di depan pasar Mayong ini juga berhubungan dengan adanya hambatan samping di sekitar pasar.

Pedoman Kapasitas Jalan 2014, dijelaskan bahwa terdapat karakteristik lainnya yang mempengaruhi nilai kapasitas ruas jalan, 
selain segmen jalan. Karakteristik tersebut yaitu hambatan samping dan ukuran kota. Dari penelitian yang dilakukan oleh Faried Hambatan samping yang berasal dari penyeberang jalan, pejalan kaki, mobil parkir ataupun bus berhenti, dan kendaraan keluar masuk menyebabkan penurunan pada kinerja jalan (Audie dan Rumanyar, 2018; Desembardi, 2018; Darmawan, 2017) . Situasi seperti ini hampir sama terjadi di ruas jalan depan Pasar Mayong. Hambatan samping ini menyebabkan ruas jalan depan pasar Mayong ini menjadi lebih sempit saat jam-jam sibuk, sehingga kecepatan berkurang dan kapasitas jalan berkurang, sehingga berakibat pada kemacetan lalu lintas.

Masalah di atas melatarbelakangi kajian ini, untuk mengetahui bagaimana pengaruh hambatan samping terhadap kinerja arus lalu lintas di ruas jalan depan Pasar Mayong, Jepara.

Kriteria kinerja lalu lintas dapat ditentukan berdasarkan nilai derajat kejenuhan atau kecepatan tempuh pada suatu kondisi jalan tertentu yang terkait dengan geometrik, arus lalu lintas, dan lingkungan jalan untuk kondisi eksisting maupun untuk kondisi desain.

Menurut PKJI (2014), arus lalu lintas (Q) merupakan jumlah kendaraan bermotor yang melalui suatu titik pada suatu penggal jalan per satuan waktu yang dinyatakan dalam satuan kend/jam (Qkend), atau skr/jam (Qskr), atau skr/hari (LHRT).

Jika diaplikasikan dalam bentuk rumus maka $\mathrm{Q}=\mathrm{N} / \mathrm{T}$, dimana $\mathrm{Q}$ adalah arus lalu lintas (kendaraan/jam), $\mathrm{N}$ adalah jumlah kendaraan yang lewat (kendaraan) dan $\mathrm{T}$ adalah waktu atau periode pengamatan (jam).

Tujuan dilakukan pengukuran arus lalu lintas adalah untuk mengetahui jumlah setiap jenis kendaraan yang melewati ruas jalan tertentu dalam satuan waktu, sehingga dapat dihitung lalu lintas harian rata-rata.

Untuk menenentukan arus lalu lintas, terlebih dahulu dengan cara membagi tiap jenis kendaraan sesuai klasifikasi jenis kendaraan, yaitu sepeda motor, kendaraan ringan dan kendaraan berat.

Menurut PKJI (2014), hambatan samping adalah kegiatan di samping segmen jalan yang berpengaruh terhadap kinerja lalu lintas.

1. Jumlah pejalan kaki berjalan atau menyeberang sepanjang segmen jalan (bobot 0,5).

2. Jumlah kendaraan berhenti dan parkir (bobot 1,0).

3. Jumlah kendaraan bermotor yang masuk dan keluar dari lahan samping jalan dan jalan samping (bobot 0,7 ).

4. Jumlah kendaraan lambat (bobot 0,4).

Menurut PKJI (2014), kapasitas merupakan arus lalu lintas maksimum dalam satuan ekr/jam yang dapat dipertahankan sepanjang segmen jalan tertentu dalam kondisi tertentu, yaitu yang melingkupi geometrik, lingkungan, dan lalu lintas. Kapasitas jalan dihitung menggunakan persamaan 1.

$$
\mathrm{C}=\mathrm{C}_{0} \times \mathrm{FC}_{\llcorner J} \times \mathrm{FC}_{\mathrm{PA}} \times \mathrm{FC}_{\mathrm{HS}} \times \mathrm{FC}_{\mathrm{UK}}
$$

Dimana:

C adalah kapasitas, skr/jam

$\mathrm{C}_{0} \quad$ adalah kapasitas dasar, skr/jam

$\mathrm{FC}_{\llcorner\lrcorner}$adalah faktor penyesuaian kapasitas terkait lebar lajur atau jalur lalu lintas

FC $_{P A}$ adalah faktor penyesuaian kapasitas terkait pemisahan arah, hanya pada jalan tak terbagi

\section{METODE}

kajian ini dilakukan di depan Pasar Mayong, Jepara. Pasar Mayong terletak di ruas jalan 
Penerapan Hambatan ... (Adib/ hal 171-178)

Jepara - Kudus, tepatnya berada di kecamatan Mayong, Jepara. Peta lokasi kajian dan denah lokasi pasar Mayong dapat dilihat pada Gambar 1 dan Gambar 2.

Waktu kajian ini berlangsung selama 3 hari, yaitu Hari Kamis, 4 Juni 2020 (Pukul 07.00 08.00, pukul 11.00 - 12.00 dan pukul 15.30 - 16.30), Hari Jumat, 5 Juni 2020 (Pukul 07.00 - 08.00, pukul 13.00 - 14.00 dan pukul 15.30 - 16.30), dan Hari Minggu, 7 Juni 2020 (Pukul 07.00 - 08.00, pukul 11.00 - 12.00 dan pukul 15.30 - 16.30).

Langkah awal yang dilakukan adalah menentukan jenis kendaraan berdasarkan klasifikasi kendaraan yaitu sepeda motor $(\mathrm{SM})$, kendaraan ringan (KR), kendaraan berat $(\mathrm{KB})$. Pengumpulan data dilakukan dengan cara menghitung langsung jumlah kendaraan yang melewati titik pengamatan dengan menggunakan pencatatan secara manual (handy tally counter) setiap 15 menit selama jam sibuk.

Survei dilakukan oleh 2 surveyor pada titik pengamatan untuk setiap arah lalu lintas. Kemudian pencatatan kecepatan kendaraan, dilakukan untuk mengukur kecepatan dibatasi pada jarak per 200 meter, yang dilakukan sebanyak 5 kali

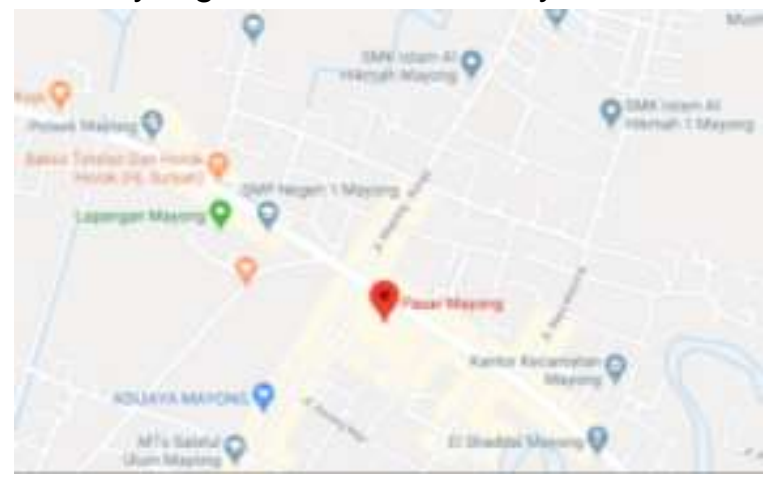

Gambar 1. Peta Lokasi Pasar Mayong, Jepara (Sumber: Google Maps). dengan mengikuti arus kendaraan untuk masing-masing arah.

Pengumpulan data geometrik jalan dilakukan dengan mengukur panjang segmen jalan yang diteliti kemudian menentukan bagian per segmen dan mengukur lebar jalan serta lebar bahu jalan.

Pelaksanaan survei untuk pengambilan data hambatan samping dilakukan dengan cara mengamati dan mencatat aktivitas samping jalan yang terjadi selama waktu pengamatan. Survei hambatan samping dilakukan dengan cara menghitung langsung setiap tipe kejadian per 200 meter pada lajur jalan yang diamati.

Tipe kejadian yang dicatat adalah jumlah kendaraan parkir di pinggir jalan, jumlah pejalan kaki yang menyeberang dan melewati pinggiran ruas jalan, arus kendaraan lambat serta jumlah angkutan yang menaik/ turunkan penumpang di segmen pengamatan. Survei dilakukan oleh dua surveyor pada lajur jalan per 100 meter, dimana setiap surveyor menghitung semua tipe kejadian per 100 meter per jam. Tahapan kajian digambarkan pada bagan alir Gambar 3.

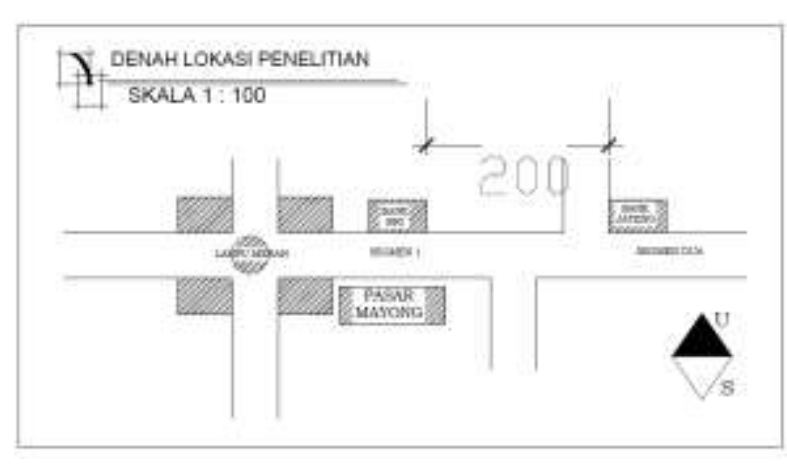

Gambar 2. Denah Lokasi Pasar Mayong, Jepara. 


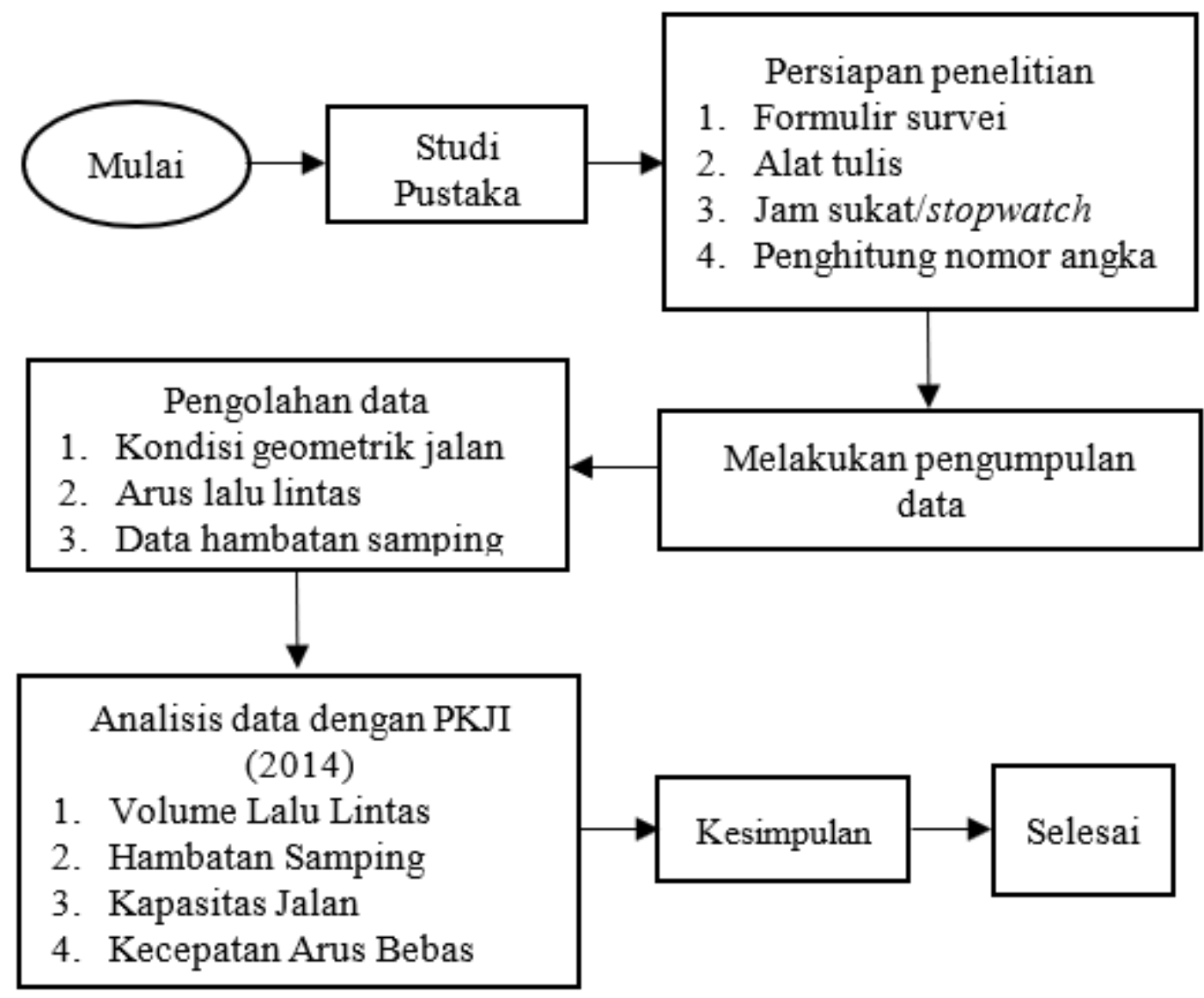

Gambar 3. Tahapan kajian

\section{HASIL DAN PEMBAHASAN}

Jumlah penduduk yang diambil dari badan pusat statistik adalah 1.240.600 jiwa. Dalam hal ini, menurut PKJI (2014) adalah termasuk kota besar karena berada di antara 1 juta dan 3 juta jiwa.

Ruas jalan depan pasar Mayong, Jepara merupakan jalan 2 lajur tak terbagi (2/2 UD), lebar jalur 6,00 meter, terdapat bahu jalan, kondisi medan lurus dan datar, tidak terdapat median. Daerah di pinggir jalan berupa pertokoan dan warung-warung.

Pengolahan data dengan cara mengkonversi setiap jenis kendaraan (kend/jam) dengan ekivalensi mobil penumpang (ekr) berdasarkan PKJI (2014) yaitu : sepeda motor $(0,25)$, kendaraan ringan $(1,00)$, dan kendaraan berat $(1,20)$.

Hasil analisis data arus lalu lintas dilakukan pada Kamis, 4 Juni 2020, Jumat, 5 juni 2020, dan Minggu, 7 Juni 2020. Hasil analisis arus lalu lintas dapat dilihat pada Tabel 1 sampai dengan Tabel 3. Rekapitulasi arus lalu lintas tertinggi disajikan pada Tabel 4. Berdasarkan hasil kajian diperoleh arus lalu lintas tertinggi yaitu pada Hari Kamis, 4 Juni 2020 pukul 15.30 - 16.30 sebesar 887,35 kend/jam. 
Penerapan Hambatan ... (Adib/ hal 171-178)

Tabel 1. Hasil analisis arus lalu lintas pada hari Kamis, 4 Juni 2020.

\begin{tabular}{|c|c|c|c|c|c|}
\hline \multirow[t]{2}{*}{ Pukul } & \multicolumn{2}{|c|}{ Arus total dari Kudus } & \multicolumn{2}{|c|}{ Arus total dari Jepara } & \multirow{2}{*}{$\begin{array}{c}\text { Total } \\
\text { (kend/jam) }\end{array}$} \\
\hline & (kend/15') & (kend/jam) & (kend/15') & (kend/jam) & \\
\hline $07.00-07.15$ & 93,1 & & 56,55 & & \\
\hline $07.15-07.30$ & 91,05 & & 62,35 & & \\
\hline $07.30-07.45$ & 108,4 & & 68,75 & & \\
\hline $07.45-08.00$ & 110,75 & 403,3 & 66,6 & 254,25 & 657,55 \\
\hline $11.00-11.15$ & 123,05 & & 69,8 & & \\
\hline $11.15-11.30$ & 103,2 & & 68,4 & & \\
\hline $11.30-11.45$ & 145,35 & & 66,75 & & \\
\hline $11.45-12.00$ & 125,9 & 497,5 & 76,1 & 281,05 & 778,55 \\
\hline $15.30-15.45$ & 153,45 & & 73,55 & & \\
\hline $15.45-16.00$ & 154,8 & & 82,05 & & \\
\hline $16.00-16.15$ & 132,35 & & 84,95 & & \\
\hline $16.15-16.30$ & 133,4 & 574 & 72,8 & 313,35 & 887,35 \\
\hline
\end{tabular}

Tabel 2. Hasil analisis arus lalu lintas pada hari Jumat, 5 juni 2020.

\begin{tabular}{cccccc}
\hline \multirow{2}{*}{ Pukul } & \multicolumn{2}{c}{ Arus total dari Kudus } & \multicolumn{2}{c}{ Arus total dari Jepara } & Total \\
\cline { 2 - 5 } & (kend/15') & (kend/jam) & (kend/15') & (kend/jam) & (kend/jam) \\
\hline $07.00-07.15$ & 55,9 & & 51,55 & & \\
$07.15-07.30$ & 91,8 & & 52,6 & & \\
$07.30-07.45$ & 65,4 & & 59,05 & & \\
$07.45-08.00$ & 94,45 & 307,55 & 53 & 216,2 & 523,75 \\
$11.00-11.15$ & 87,5 & & 55,65 & & \\
$11.15-11.30$ & 106,45 & & 51,6 & & \\
$11.30-11.45$ & 110,6 & & 55,3 & & \\
$11.45-12.00$ & 99,55 & 404,1 & 59,55 & 222,1 & 626,2 \\
$15.30-15.45$ & 79,1 & & 58,55 & & \\
$15.45-16.00$ & 127,7 & & 64,4 & & \\
$16.00-16.15$ & 102,1 & & 75,95 & & \\
$16.15-16.30$ & 110,85 & 419,75 & 65,85 & 264,75 & 684,5 \\
\hline
\end{tabular}

Tabel 3. Hasil analisis arus lalu lintas pada hari Minggu, 7 Juni 2020.

\begin{tabular}{cccccc}
\hline Pukul & \multicolumn{2}{c}{ Arus total dari Kudus } & \multicolumn{2}{c}{ Arus total dari Jepara } & Total \\
\cline { 2 - 5 } & (kend/15') & (kend/jam) & (kend/15') & (kend/jam) & (kend/jam) \\
\hline $07.00-07.15$ & 79,05 & & 50,25 & & \\
$07.15-07.30$ & 76,85 & & 53,05 & & \\
$07.30-07.45$ & 79,65 & & 55 & & \\
$07.45-08.00$ & 94,85 & 330,4 & 57,1 & 215,4 & 545,8 \\
$11.00-11.15$ & 97,4 & & 59,75 & & \\
$11.15-11.30$ & 113,8 & & 56,9 & & \\
$11.30-11.45$ & 105,75 & & 61,25 & & \\
$11.45-12.00$ & 104,95 & 421,9 & 59,85 & 237,75 & 659,65 \\
$15.30-15.45$ & 90,85 & & 66,2 & & \\
$15.45-16.00$ & 94,25 & & 64 & & \\
$16.00-16.15$ & 100 & & 62,8 & & \\
$16.15-16.30$ & 100,3 & 385,4 & 65,85 & 258,85 & 644,25 \\
\hline
\end{tabular}


Tabel 4. Rekapitulasi arus lalu lintas tertinggi.

\begin{tabular}{ccc}
\hline Hari & Waktu & Arus total lalu lintas (kend/jam) \\
\hline Hari Kamis, 4 Juni 2020 & $07.00-08.00$ & 657,55 \\
& $11.00-12.00$ & 778,55 \\
Hari Jumat, 5 juni 2020 & $15.30-16.30$ & 887,35 \\
& $07.00-08.00$ & 523,75 \\
& $11.00-12.00$ & 626,20 \\
Hari Minggu, 7 Juni 2020 & $15.30-16.30$ & 684,50 \\
& $07.00-08.00$ & 545,80 \\
& $11.00-12.00$ & 659,65 \\
\hline
\end{tabular}

Pengambilan data hambatan samping dilakukan dengan cara menghitung banyaknya jumlah kejadian hambatan samping sepanjang $200 \mathrm{~m}$.

Dari data kajian hambatan samping bobot tertinggi pada segmen 1 pada hari Kamis, 4 Juni 2020 Pada waktu pelaksanaan kajian 07.00-08.00, 11.00-12.00, dan 15.30-16.30 menunjukan angka tertinggi dari hambatan samping segmen 1 itu adalah pukul 15.3016.30 dengan frekunsi kejadian adalah 479 angka ini menunjukan bahwa terjadinya hambatan samping arus lalu lintas dikarenakan ruas jalan depan pasar Mayong mengalami hambatan samping dampak waktu orang pulang dalam pekerjaan di kantor. Dan segmen 2 hari Kamis, 4 Juni 2020. Pada waktu pelaksanaan kajian 07.00-08.00, 11.0012.00, dan 15.30-16.30 menunjukan angka tertinggi dari hambatan samping segmen 2 itu adalah pukul 11.00-12.00 dengan frekunsi kejadian adalah 485 angka ini menujukan bahwa terjadinya hambatan samping arus lalu lintas dikarenakan ruas jalan depan pasar mayong mengalami hambatan samping dampak waktu orang istirahat siang dalam pekerjaan dikantor.

Untuk mengetahui kecepatan arus bebas segmen jalan depan pasar Mayong digunakan Persamaan 2. Parameter yang digunakan dalam perhitungan di kajian ini disajikan pada Tabel 5.

$$
\mathrm{V}_{\mathrm{B}}=\left(\mathrm{V}_{\mathrm{BD}}+\mathrm{V}_{\mathrm{BL}}\right) \times F \mathrm{~V}_{\mathrm{BHS}} \times \mathrm{FV}_{\mathrm{BUK}}
$$

Dimana $V_{B D}$ merupakan kecepatan arus bebas dasar $(\mathrm{km} / \mathrm{jam}), \mathrm{V}_{\mathrm{BL}}$ adalah nilai penyesuaian kecepatan arus bebas dasar akibat lebar jalur lalu lintas efektif, $\mathrm{FV}_{\mathrm{BHS}}$ adalah faktor penyesuaian kecepatan arus bebas akibat hambatan samping, dan $\mathrm{FV}_{\mathrm{BUK}}$ adalah faktor penyesuaian untuk pengaruh ukuran kota pada kecepatan arus bebas kendaraan ringan.

Tabel 5. Parameter kecepatan arus bebas

\begin{tabular}{ll}
\hline Parameter & Nilai \\
\hline$V_{\mathrm{BD}}$ & $44 \mathrm{~km} / \mathrm{jam}$ \\
$\mathrm{V}_{\mathrm{BL}}$ & $-9,5 \mathrm{~km} / \mathrm{jam}$ \\
$\mathrm{FV}_{\mathrm{BHS}}$ & 0,90 \\
FV & 1 \\
\hline
\end{tabular}

Berdasarkan perhitungan kecepatan arus bebas menggunakan persamaan 2 diperoleh diperoleh $V_{B}$ sebesar 31,050 $\mathrm{km} / \mathrm{jam}$

Untuk menampung arus lalu lintas yang ideal dalam satuan waktu tertentu dinyatakan dalam jumlah kendaraan yang melewati potongan jalan tertentu dalam 1 jam (kendaraan/jam). Perhitungan kapasitas jalan menggunakan persamaan 1. Tabel 6 menyajikan parameter yang digunakan dalam perhitungan kapasitas jalan.

Tabel 6. Parameter kapasitas jalan

\begin{tabular}{ll}
\hline Parameter & Nilai \\
\hline $\mathrm{C}_{0}$ & 2900 \\
FC $_{\llcorner J}$ & 0,56 \\
FC $_{P A}$ & 0,90 \\
FCUK & 1 \\
\hline
\end{tabular}


Berdasarkan perhitungan menggunakan perasamaan 1 diperoleh kapasitas jalan sebesar 1.461,6 kendaraan/jam

Tingkat kinerja segmen jalan diukur menggunakan parameter dierajat jenuh. Derajat jenuh dihitung menggunakan persamaan 3 .

$$
D_{J}=\frac{Q}{C}
$$

Dengan total arus (Q) 887,3 kend/jam dan kapasitas jalan (C) 1.461,6 smp/jam maka diperoleh derajat jenuh 0,607 . Sehingga kajian sesuai prosedur PKJI.

Analisis kapasitas Jalan Perkotaan eksisting atau yang akan ditingkatkan harus selalu mempertahankan $D_{J} \leq 0,85$. Hasil analisis derajat jenuh disajikan pada Tabel 7.

Dari hasil kajian Tabel 8 Hasil analisis dan pembahasan besarnya hubungan kinerja ruas jalan amatan menggunakan analisis regresi polinomial untuk memperoleh nilai regresi nya. Adapun grafik regresi disajikan pada Gambar 4.

Berdasarkan Gambar 4 hasil analisis persamaan regresi hubungan hambatan samping (KHS) dan kecepatan (V) di ruas jalan depan pasar mayong segmen 1 mengalami hambatan samping sebesar $y=1,6179 x^{2}+74,357 x$ dan juga didapatkan koefisien determinasi (R2) sebesar 0,4238, sedangkan nilai koefisien korelasinya $(r)$ 0,651 . Hasil ini menunjukan bahwa $42 \%$ dari ketidakpastian semula telah dijelaskan oleh model.

Tabel 7. Hasil analisis derajat jenuh.

\begin{tabular}{ccc}
\hline Hari & $\begin{array}{c}\text { Derajat } \\
\text { kejenuhan }\end{array}$ & Hasil \\
\hline Kamis, 4 Juni 2020 & 0,607 & $<0,85$ \\
Jumat, 5 Juni 2020 & 0,468 & $<0,85$ \\
Minggu, 7 Juni 2020 & 0,440 & $<0,85$ \\
\hline
\end{tabular}

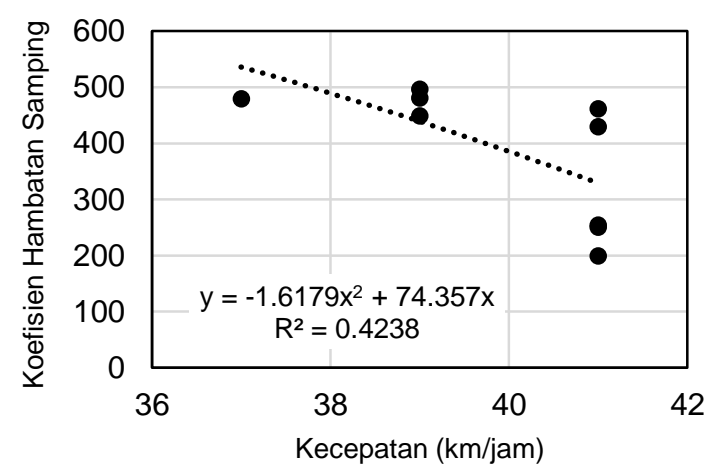

Gambar 4. Hubungan hambatan samping segmen 1 dengan kecepatan tempuh.

Tabel 8. Rekapitulasi hasil kajian

\begin{tabular}{cccccccc}
\hline \multirow{2}{*}{ Hari } & \multirow{2}{*}{ Waktu } & \multirow{2}{*}{$\begin{array}{c}\mathrm{C} \\
\text { Kend/jam })\end{array}$} & $\begin{array}{c}\mathrm{V}_{\mathrm{T}} \\
\mathrm{kmm} / \mathrm{jam})\end{array}$ & \multicolumn{2}{c}{ Hambatan Samping } & \multirow{2}{*}{ DJ } & \multirow{2}{*}{$\begin{array}{c}\mathrm{Q} \\
\text { (Kend/jam) }\end{array}$} \\
\hline Kamis, 4 Juni & $07.00-08.00$ & 1461.6 & 41 & 254 & 267 & 0.449884 & 657.55 \\
2020 & $11.00-12.00$ & 1461.6 & 39 & 496 & 485 & 0.53267 & 778.55 \\
& $15.30-16.30$ & 1461.6 & 37 & 479 & 412 & 0.607109 & 887.35 \\
\hline Jumat, 5 Juni & $07.00-08.00$ & 1461.6 & 41 & 199 & 206 & 0.35834 & 523.75 \\
2020 & $11.00-12.00$ & 1461.6 & 41 & 461 & 424 & 0.428435 & 626.20 \\
& $15.30-16.30$ & 1461.6 & 39 & 449 & 301 & 0.468322 & 684.50 \\
\hline Minggu, 7 & $07.00-08.00$ & 1461.6 & 41 & 250 & 225 & 0.373426 & 545.80 \\
Juni 2020 & $11.00-12.00$ & 1461.6 & 39 & 481 & 370 & 0.45132 & 659.65 \\
& $15.30-16.30$ & 1461.6 & 41 & 429 & 406 & 0.440784 & 644.25 \\
\hline
\end{tabular}




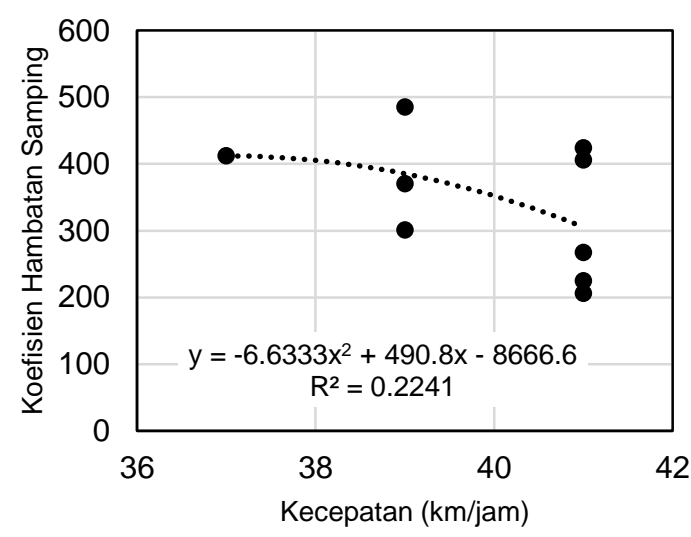

Gambar 5. Grafik. hubungan hambatan samping segmen 2 dengan kecepatan tempuh.

Berdasarkan Gambar 5 hasil analisis persamaan regresi hubungan hambatan samping dan kecepatan (V) di ruas jalan depan pasar mayong segmen 2 mengalami hambatan samping sebesar $y=-$ $6,6333 x^{2}+490,8 x-8666,6$ dan juga didapatkan koefisien determinasi (R2) sebesar 0,2241, sedangkan nilai koefisien korelasinya (r) 0,473 . Hasil ini menunjukan bahwa $22 \%$ dari ketidakpastian semula telah dijelaskan oleh model.

\section{SIMPULAN}

Berdasarkan hasil kajian dan pembahasan dapat diambil bahwa berdasarkan hasil survei dan analisis kinerja di ruas jalan depan Pasar Mayong, Jepara pada kondisi eksisting diperoleh arus total 887,35 $\mathrm{kend} / \mathrm{jam}$, frekuensi berbobot tertinggi $331,30 \mathrm{kejadian/jam,} \mathrm{kecepatan} \mathrm{arus} \mathrm{bebas}$ $31,05 \mathrm{~km} / \mathrm{jam}$, kapasitas jalan 1.461,6 kend/jam, dan derajat kejenuhan 0,607. Sehingga bisa dikatakan bahwa kecepatan arus masih stabil. Sedangkan jenis hambatan samping yang paling berpengaruh disebabkan oleh kendaraan keluar masuk jalan. Hasil analisis didapatkan hubungan hambatan samping dengan kapasitas di segmen 1 adalah $\mathrm{y}=$ -
$1,6179 x^{2}+74,357 x$ dengan menunjukan bahwa $42 \%$ dari ketidakpastian semula, dan di segmen 2 adalah $y=-6,6333 x^{2}+490,8 x-$ 8666,6 dengan menunjukan bahwa $22 \%$ dari ketidakpastian

\section{DAFTAR RUJUKAN}

Audie L. E. dan Rumayar. 2018. Pengaruh Hambatan Samping Terhadap Kinerja Ruas Jalan Raya Kota Tomohon (Studi Kasus: Persimpangan Jl. Pesanggrahan - Persimpangan $\mathrm{Jl}$. Pasuwengan)

Direktorat Jenderal Bina Marga. 1997. Manual Kapasitas Jalan Indonesia (MKJI). Jakarta: Kementrian Pekerjaan Umum.

Direktorat Jenderal Bina Marga. 2014. Pedoman Kapasitas Jalan Indonesia (PKJI). Jakarta: Kementrian Pekerjaan Umum.

Faried Desembardi. 2018. Analisis Kinerja Ruas Jalan Terhadap Pengaruh Hambatan Samping pada Jalan A.M. Sangaji Gonof Km.12 Kota Sorong

Pratama, G. N. I. P. P., \& Najihan, H. F. (2020, September). The Effect of Beach Sands to Replacement of Fine Aggregate with Addition Filler of Ash Cane on the Asphalt Mixture on Marshall Characteristics. In Journal of Physics: Conference Series (Vol. 1625, No. 1, p. 012032). IOP Publishing.

Pratama, G. N. I. P., \& Sumarjo, H. (2018). Aksesibilitas Tata Letak Elevator Penumpang Gedung Kantor Pusat Layanan Terpadu (KPLT) Fakultas Teknik UNY. INformasi dan Ekspose hasil Riset Teknik SIpil dan Arsitektur, 14(1), 26-35.

Weka Indra Darmawan. 2017. Model Pengaruh Hambatan Samping Terhadap Kinerja Jalan Perkotaan di Jalan Imam Bonjol Bandar Lampung. 